\title{
Socially Responsible Investments: An International Empirical Study Of Time-Varying Risk Premiums
}

Hachmi Ben Ameur, INSEEC Business School, France Jérôme Senanedsch, INSEEC Business School, France

\begin{abstract}
This paper empirically analyses the performance of Socially Responsible Investments (SRI) by applying an asymmetric BEKK GARCH model which estimates conditional systematic risk and varying risk premiums. We evaluate the performance of SRI from an international perspective, comparing sustainable indexes with conventional indexes, and we apply our model to three regions: the USA, Europe, and Asia Pacific. We respectively compare the Dow Jones Sustainability United States Index, the Dow Jones Sustainability Europe Index, and the Dow Jones Sustainability Asia/Pacific Index with conventional indexes, namely the Dow Jones Industrial Average, the Dow Jones Europe Index, and the Dow Jones Asia/Pacific Index. Our model estimations are based on weekly data from January 2004 to November 2013. Our results show that sustainable indexes exhibit lower risk premiums than conventional ones. However each of the three regions studied has its own specificity in terms of investor behavior toward SRI, including the impact of the subprime mortgage crisis.
\end{abstract}

Keywords: Socially Responsible Investments; Corporate Social Responsibility; Time-Varying Risk Premiums

\section{INTRODUCTION}

n recent years the literature has become increasing interested in socially responsible investment (SRI)
opportunities, while SRI funds are also rapidly growing in popularity. SRI involves a decision-making
process based on corporate social responsibility (CSR) standards that integrate social, environmental, and ethical dimensions. SRI follows conventional financial theory, incorporating a filter which excludes assets considered as non-responsible (alcohol, tobacco, gambling, defense, etc.).

The question of SRI performance is of particular interest as it can help us to understand portfolio management concepts such as investor utility and decision-making. For instance, Bollen (2007) analyses the utility function for SRI investors based on a multi-attribute function that encompasses ethical values. Renneboog et al. (2008a) commented on this model by questioning whether investors are willing to pay for CSR and whether CSR is incorporated into the share prices. Arguments defending CSR performance are multiple and are generally linked to stakeholder theory. In fact, CSR is considered to reduce the cost of conflict (Heal, 2005), attract the best workers (Fishman et al., 2006) and increase a firm's value through higher prices combined with lower output (Allen et al., 2007). Others argue that organizations implement CSR strategies because of pressure from environmental or social lobbyists (Baron, 2001). Barnea and Rubin (2010) also analyzed the motivations behind CSR strategies and showed that managers may be looking to improve their reputation and thus contribute to higher agency costs. In terms of empirical performance evaluation, Orlitzky et al. (2003) used a meta-analysis of 52 studies to show that CSR is related to past and future financial performance. Klassen and McLaughlin (1996), on the other hand, published empirical findings that identified significant positive abnormal returns after firms won awards based on their social or environmental performance.

SRI needs to be understood in the context of portfolio management. The efficient market hypothesis provides a framework to understand the likelihood that SRI outperforms conventional investments. The basic 
premise is that SRI excludes some assets and creates portfolio diversification limitations, and cannot, all other things being equal, provide abnormal returns. SRI can, at best, achieve exactly the same performance as the benchmark. If SRI can in fact provide empirical abnormal returns, these should be added to the list of efficient market anomalies. On the contrary, if SRI underperforms the conventional benchmark, it would prove that investors are willing to pay for their ethical values. Several studies have empirically evaluated SRI fund performance. Some papers have reached the conclusion of neutral performance (Blanchett, 2010), others a positive performance (Lyn \& Zychowicz, 2010), and yet others a negative performance (Adler \& Kritzman, 2008). However, such studies are based on different methodologies, benchmarks, dates, data intervals, CSR filters, and countries. These factors may explain the differing results. More research needs to be conducted in this area to understand whether or not SRI funds can provide financial value.

The literature also contains some papers that focus on the risk-return associated with SRI equity indexes. These studies are interesting because they are based on a general analysis of the market and not on the performance of funds whose management is sometimes opaque. Most of the papers in this field conclude that SRI index performance is very similar to conventional indexes (Sauer, 1997; DiBartolomeo \& Kurtz, 1999) and that investors do not need to pay to follow their values and beliefs. However, Statman (2006) proved that DSI returns (1990-2004) were generally higher than those of the S\&P 500 Index, but were non-significant after taking the level of risk into account. Collison et al. (2008) evaluated the performance of the FTSE4Good indexes and concluded that they outperformed the conventional benchmarks (1996-2005). The authors also argued that most of these results were due to risk differences between the FTSE4Good indices and the conventional benchmarks.

It appeared to us that risk evaluation was one of the main issues in the literature SRI. In this paper, we focus on estimating the level of risk supported by SRI compared to conventional investments. The efficient market hypothesis argues that SRI performance should be lower than conventional investments, while stakeholder concepts postulate that SRI should experience a lower level of risk given its selection of firms with strict CSR policies. Moreover, CSR is more likely to create financial value due to higher returns or lower volatility (Bollen, 2007).

To evaluate the risk of SRI, we applied an asymmetric BEKK GARCH model which provides a measure of conditional volatilities. To this end, we applied the model to 3 different zones, the US, Europe, and Asia Pacific, to obtain an international perspective using sustainable indexes compared to conventional ones. Our paper is organized as follows. Section 2 develops our model used to evaluate SRI performance. Section 3 describes our data and comments on our results. Section 4 concludes.

\section{METHODOLOGY}

\section{Conditional CAPM Model}

To evaluate the relationship between financial asset risk and return, the Capital Asset Pricing Model (CAPM) developed by Sharpe (1966) is certainly the most popular. The simple CAPM equation can be written as:

$$
E\left(R_{i}\right)=R_{F}+\beta_{i}\left[E\left(R_{M}\right)-R_{F}\right]
$$

where $E\left(R_{i}\right)$ is the expected return on stock $i, R_{F}$ is the risk-free rate, $E\left(R_{M}\right)$ is the expected return on market portfolio, $\beta_{i}$ is the systematic risk of stock $i$ or the definition of market sensitivity parameter, and $E\left(R_{M}\right)-R_{F}$ is the expected market risk premium.

In risk premium form, the CAPM equation can be written as:

$$
E\left(R_{i}\right)-R_{F}=\beta_{i}\left[E\left(R_{M}\right)-R_{F}\right]
$$


with $\quad \beta_{i}=\frac{\operatorname{cov}\left(R_{i}, R_{M}\right)}{\operatorname{Var}\left(R_{M}\right)}$

where $\sigma_{i M}$ is the covariance between returns on the individual asset $i$ and returns on the fully diversified market portfolio, and $\sigma_{M}^{2}$ is the variance of the market portfolio.

The empirical CAPM equation is as follows:

$E\left(R_{i}\right)-R_{F}=\alpha+\beta_{i}\left[E\left(R_{M}\right)-R_{F}\right]+\varepsilon_{i}$

Numerous empirical studies have evaluated the relevance of CAPM, which analyses stock and portfolio returns only on $\beta$ measure relatively to market index. In fact, this model is based on the assumption that the investors share the same expectations with regard to distribution characteristics (Jagannathan \& Wang, 1996). These studies (Engle, 1982; Bollerslev, 1986) show that return distribution varies over time. Bollerslev et al. (1988) tested the standard CAPM model for several financial indexes with findings in favor of beta variability. In this respect, the main accepted idea is that investors still share identical expectations of moments of first and second orders, but these moments are conditional on the information at time $t$.

This model is called the Conditional CAPM and its simple version can be written as:

$$
E\left(R_{i} \mid I_{t}\right)-R_{F}=\beta_{i}\left[E\left(R_{M} \mid I_{t}\right)-R_{F}\right]
$$

The empirical Conditional CAPM equation is as follows:

$$
E\left(R_{i} \mid I_{t}\right)-R_{F}=\alpha+\beta_{i}\left[E\left(R_{M} \mid I_{t}\right)-R_{F}\right]+\varepsilon_{i}
$$

where $R_{F}$ is the one-period risk free rate, $E\left(R_{i} \mid I_{t}\right)$ and $E\left(R_{M} \mid I_{t}\right)$ are the one-period expected return on portfolio $i$ and the one-period expected market return portfolio, conditional on the available information $I_{t}$. In this model, $\beta_{i}$ is conditional on the time variation and can be written as:

$$
\beta_{i}=\frac{\operatorname{cov}\left(R_{i}, R_{M} \mid I_{t}\right)}{\operatorname{Var}\left(R_{M} \mid I_{t}\right)}
$$

To estimate the Conditional CAPM, we used a multivariate GARCH model.

\section{Asymmetric BEKK GARCH Model}

As mentioned above, there is empirical evidence that financial time series volatilities are not constant but instead are time-varying. They can be modeled by multivariate GARCH models. These models have been used in many fields, as in the study by Fatoum et al. (2014) which analyzed the characteristics of risk premiums in emerging markets and the study by Nikkinen et al. (2013) which examined the transmission of the US subprime crisis across the BRIC financial markets. This allows us to consider non-Gaussian returns, such as yields following a conditional Gaussian distribution. The BEKK GARCH model has been presented and analyzed in detail by Engle and Kroner (1995). Like BEKK GARCH models, multivariate GARCH with a "diagonal-vector" form provide us with a tool to estimate time-varying correlations. We applied an asymmetric BEKK GARCH model which enables us to consider the level of asymmetry in the returns; i.e., the fact that stock market volatility increases more after a negative shock than after a positive shock of the same size. 
Thus, we consider:

$$
\begin{aligned}
& y_{t}=\mu_{t}+\varepsilon_{t} \\
& \varepsilon_{t} \rightarrow N\left(0, H_{t}\right) \\
& H_{t}=C^{\prime} C+\sum_{k=1}^{K} \sum_{i=1}^{q} A_{i K}^{\prime} \varepsilon_{t-i} \varepsilon_{t-i}^{\prime} A_{i k}+\sum_{k=1}^{K} \sum_{j=1}^{p} B_{j k}^{\prime} H_{t-j} B_{j k}
\end{aligned}
$$

With parameters $(\mathrm{C}, \mathrm{A}, \mathrm{B})$, matrix $\mathrm{C}$ is $(\mathrm{d} * \mathrm{~d})$-dimensional, $\mathrm{C}>0$, and $\mathrm{A}$ and $\mathrm{B}$ are $(\mathrm{d} * \mathrm{~d})$-dimensional real matrices. In view of the paired matrices, symmetry and non-negative definiteness of the conditional variance matrix, $H t$ is ensured by the pairing of each matrix (A, B, and C) with its transpose (see Engle \& Kroner, 1995). The BEKK model is sufficiently general to include all of the positive definite diagonal representations, and nearly all of the positive definite vector representations.

Kroner and $\mathrm{Ng}$ (1998) developed an extension of the BEKK model to take into account the fact that stock variance and covariance tend to rise more in response to negative shocks (bad news) than positive ones (good news). The asymmetric model is the same as the BEKK model, except for the covariance-variance matrix, which is defined as follows:

$$
H_{t}=C^{\prime} C+\sum_{k=1}^{K} \sum_{i=1}^{q} A_{i K}^{\prime} \varepsilon_{t-i} \varepsilon_{t-i}^{\prime} A_{i k}+\sum_{k=1}^{K} \sum_{i=1}^{q} D_{i k}^{\prime} \zeta_{t-i} \zeta_{t-i}^{\prime} D_{i k}+\sum_{k=1}^{K} \sum_{j=1}^{p} B_{j k}^{\prime} H_{t-j} B_{j k}
$$

where $\mathrm{D}$ is a $(\mathrm{d} * \mathrm{~d})$-dimensional parameter and $\zeta \mathrm{t}$ is the asymmetric term, the variable $\zeta \mathrm{t}$ is defined as $\varepsilon \mathrm{t}$ if $\varepsilon t$ is negative and zero if not. These terms allow us to capture the asymmetric property of the time-varying variancecovariance.

The quasi-maximum likelihood estimation (QML) by Bollerslev and Wooldridge (1992) allows inference when the conditional distribution of the residuals is non-normal.

This model enables us to determine the time-varying beta directly from the matrix $H_{t}$ :

$$
\beta_{i, t}=\frac{\hat{H}_{12, t}}{\hat{H}_{22, t}}
$$

with $\hat{H}_{22, t}$ and $\hat{H}_{12, t}$ respectively the conditional volatilities of the global portfolio market and the conditional covariance between asset $i$ and the global portfolio market.

\section{DATA AND DESCRIPTIVE STATISTICS}

We applied an asymmetric BEKK GARCH model on 3 different geographies zones, the USA, Europe, and Asia Pacific, to obtain an international perspective using sustainable indexes, respectively, Dow Jones Sustainability United States Index, Dow Jones Sustainability Europe Index, Dow Jones Sustainability Asia/Pacific Index compared to conventional indexes, namely, Dow Jones Industrial Average, Dow Jones Europe Index, and Dow Jones Asia/Pacific Index. We estimated our model using weekly data from January 2004 to November 2013.

Empirically, our model used the Dow Jones Global Total Stock Market Index and the US 3-month treasury bill bonds respectively for $R_{m}$ and $R_{f}$. 
Table 1: Descriptive Statistics

\begin{tabular}{|l|c|c|c|c|c|c|}
\cline { 2 - 7 } \multicolumn{1}{c|}{} & $\begin{array}{c}\text { Dow Jones } \\
\text { USA }\end{array}$ & $\begin{array}{c}\text { Dow Jones } \\
\text { Sustainability } \\
\text { USA }\end{array}$ & $\begin{array}{c}\text { Dow Jones } \\
\text { Europe }\end{array}$ & $\begin{array}{c}\text { Dow Jones } \\
\text { Sustainability } \\
\text { Europe }\end{array}$ & $\begin{array}{c}\text { Dow Jones } \\
\text { Asia Pacific }\end{array}$ & $\begin{array}{c}\text { Dow Jones } \\
\text { Sustainability Asia } \\
\text { Asia Pacific }\end{array}$ \\
\hline Mean & 0.0008 & 0.0006 & 0.0011 & 0.0006 & 0.0010 & 0.0009 \\
\hline Median & 0.0018 & 0.0010 & 0.0036 & 0.0019 & 0.0018 & 0.0025 \\
\hline Maximum & 0.1128 & 0.1025 & 0.1473 & 0.1283 & 0.0766 & 0.0958 \\
\hline Minimum & -0.1815 & -0.1674 & -0.2308 & -0.2222 & -0.1781 & -0.1827 \\
\hline Std. Dev & 0.0238 & 0.0236 & 0.0325 & 0.0276 & 0.0262 & 0.0280 \\
\hline Skewness & -0.6181 & -0.5459 & -1.0200 & -1.1325 & -0.8571 & -0.7716 \\
\hline Kurtosis & 11.1283 & 9.7738 & 10.1264 & 13.3674 & 7.6609 & 7.0731 \\
\hline Jarque-Bera & $1.4393 e+003$ & $1.0023 e+003$ & $1.1699 \mathrm{e}+003$ & $2.3977 \mathrm{e}+003$ & 525.0999 & 403.9465 \\
\hline
\end{tabular}

The mean returns of the six indices are positive. The USA exhibits the lowest standard deviation for the standard and sustainable indices while the Dow Jones Europe has the highest standard deviation. The European debt crisis can help to explain this result. Skewness measures the probability distribution asymmetry; negative values for the six indices indicate that data are skewed left, and positive excess kurtosis means that the distribution has fatter tails than a normal distribution.

\section{EMPIRICAL RESULTS}

Figure 1 shows the conditional volatility of conventional and sustainable indexes for the following regions: the USA, Europe, and Asia Pacific. It may be noted that conditional volatilities of sustainable and standard indexes follow the same trend, with higher levels for the standard indexes except in the Asia Pacific region. Moreover, the financial crisis of 2008 is clearly visible in the data with a high level of volatility. This confirms the findings in the literature which suggest that, in the long term, ISR should exhibit less specific risk than traditional investments.
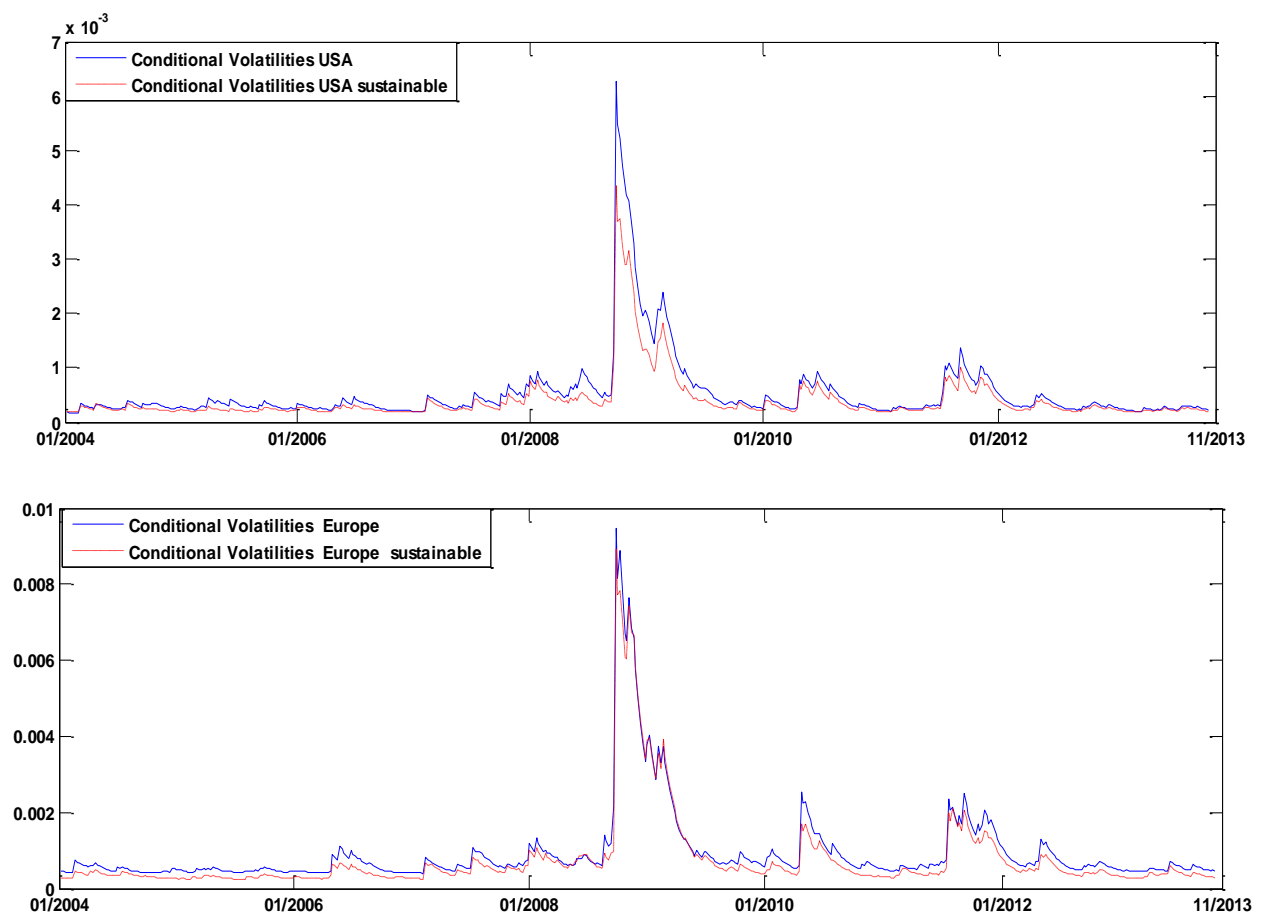

Figure 1: Conditional Volatilities 


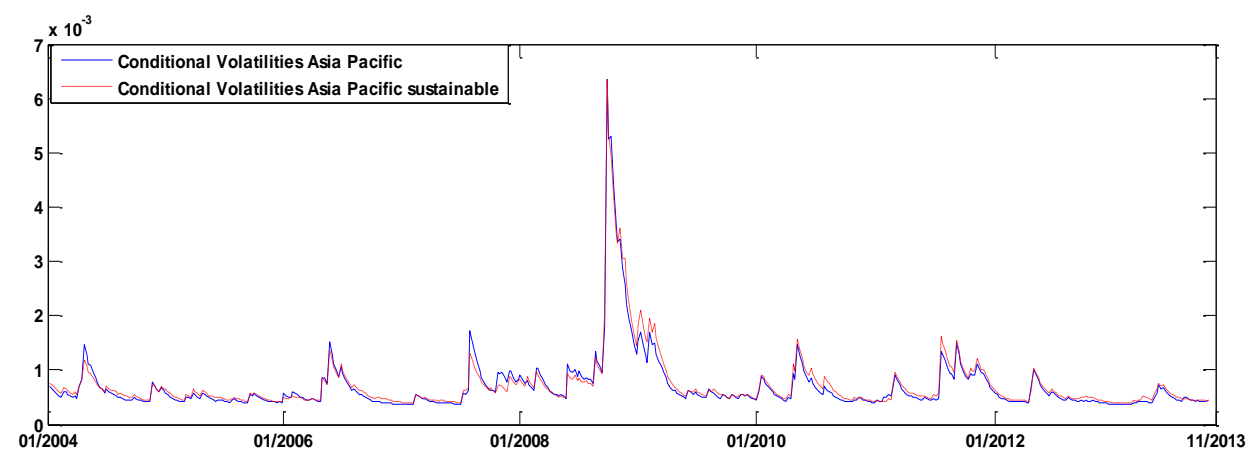

Figure 1 cont.

Figure 2 displays both sustainable and conventional time-varying betas for our 3 study regions. It shows very distinctive beta variability, justifying our decision to apply a conditional CAPM.

We studied the evolution of time-varying risk premiums and, to this end, performed an analysis of the conditional betas. Figure 3 displays the results for our entire sample. Tables 2, 3, and 4 provide details of our findings for respectively the USA, Europe, and Asia Pacific, with the original sample divided into 3 sub-periods: 01/2004-07/2007, 08/2007-08/2011, and 09/2011-11/2013. Table 5 shows the asymmetric parameters and the significance of our results. We found that, for all the indexes, varying risk premiums experience negative levels in times of crisis. The results highlight the large losses incurred on the Dow Jones Global Total Stock Market Index.

More precisely, for the USA, we note that conditional betas from the Dow Jones Industrial Average operated at very similar levels between 2004 and 2011. Sustainable conditional betas are more volatile. Standard betas are always higher than sustainable ones and the spread between them is not stable. It was particularly wide in the sub period 2007-2011, as illustrated in Table 1. These results can be explained by the conditional volatility peak encountered during the crisis, as shown in Figure 1. This does not have a general impact on sustainable stocks which experience low betas. Concerning the US risk premiums for the entire sample, their level is positive in sub-periods 1 and 3 and negative in sub-period 2, which was characterized by the subprime crisis. In general, a negative risk premium occurs when a risk-free asset pays a higher premium than a risky one. Risk premium yields are almost always positive, but in some cases, fluctuations in the market induce negative risk premiums. In the first sub-period, the varying risk premium is slightly higher for the standard index (0.0017 vs 0.0016$)$ which shows that investors demand a higher remuneration for this type of investment compared to the CSR sector. We may note that in the last period (post-crisis period), levels of varying risk premiums were higher for both categories of indexes, which suggests that the crisis altered the general behavior of investors to some extent. However, sustainable risk premiums increased less than conventional ones. This indicates that investors are increasingly sensitive to ISR, and consider CSR as a distinguishing criterion for their portfolio selection.

Regarding Europe, conditional betas from the Dow Jones Europe Index were more aggressive ( $>1$ in sub periods 1 and 3) than the sustainable index $(<1$ in sub period 1 and 3$)$ over the entire period. Average conditional betas decreased for both the Dow Jones Sustainability Europe Index and the Dow Jones Europe Index in 2013 compared to 2004, but the sustainable index decreased to a lesser degree, which led to higher spreads in the postcrisis sub-period compared to the pre-crisis one. On the other hand, varying risk premiums increased for both indexes in 2013 compared to 2004. This increase is more or less the same for the Dow Jones Europe Index and the Dow Jones Sustainability Europe Index (approximately 0,005) as shown in Table 3. The stability of the results suggests that the crisis had no impact on investor behavior with respect to their distinctive criterion, inciting them to choose between CSR and conventional companies.

Results from the Asia Pacific region in terms of conditional betas and the level of varying risk premiums are not very different from those of the other areas we studied. In general, the average conditional betas of the Dow Jones Asia/Pacific Index are, for each period, higher than those of the Dow Jones Sustainability Asia/Pacific Index. The crisis did not change this trend. Compared to the USA, the levels of mean betas and risk premium are much 
higher, even if the crisis led to a narrower spread. Compared to Europe, sustainable betas remain higher while standard betas are lower, which shows that investors on the Asian Pacific sustainable market still consider ISR to be safer, but are less sensitive to the issue than investors from the European market. Indeed, investors demand additional compensation for investing in CSR firms in Asia Pacific compared to Europe. This can be explained by the fact that SRI assets in this region represent less than $1 \%$ of total SRI assets in the world, ${ }^{1}$ and that there is a relative lack of information regarding such stocks.

Generally speaking, our results indicate lower systematic risk of sustainable indexes in the USA, Europe, and the Asia Pacific region. As mentioned above, our study findings are consistent with the major results in the literature on CSR which, in general, suggest a reduction in risk because of their relation with stakeholder principles. These results are consequently not consistent with Renneboog et al. (2008b).

Thus, for now, investing in Asia Pacific CSR remains less risky than investing in the conventional market. However, the risk difference is lower than for the USA and Europe. We cannot consider that this is due to a higher degree of market efficiency compared to the American and European markets. On the contrary, the findings may be explained by the lower level of investor interest in Asian Pacific CSR firms as local investors are less sensitive to the issue and companies are less inclined to communicate on CSR principals. In our view, the basis of organizations is trust and investors may not consider CSR trustworthy enough to invest massively in them as they do with conventional companies.

In the period of crisis from $08 / 2007$ to $08 / 2011$, the results show the same trend as in the rest of the sample. In Europe, where the conventional index is the most aggressive in our sample, investors appear to keep the same motivation and level of rationality when they make strategic portfolio decisions about SRI. Europe seems to be a precursor for SRI and the USA has followed the trend. The crisis has altered investment choice criteria to some extent as the level of conditional betas shows that the market makes a clearer distinction between conventional and sustainable investment.
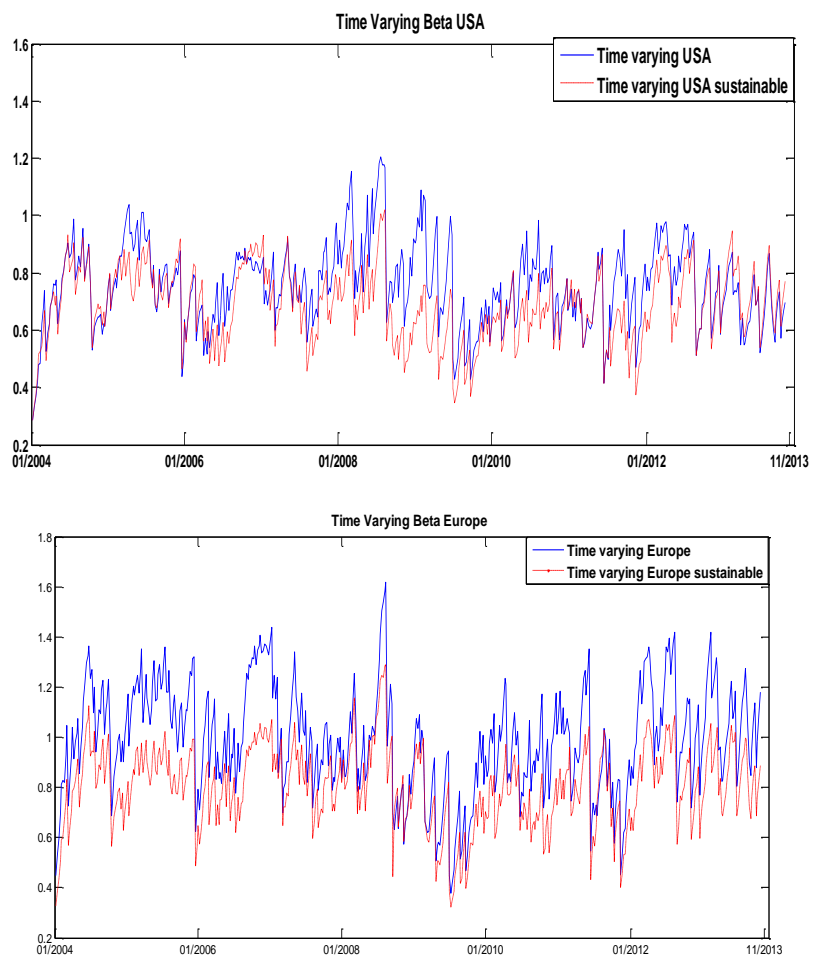

Figure 2: Time-Varying Betas

${ }^{1}$ Eurodif (2012): the European SRI study highlights the scale of the European SRI market and analyzes the international SRI industry. 


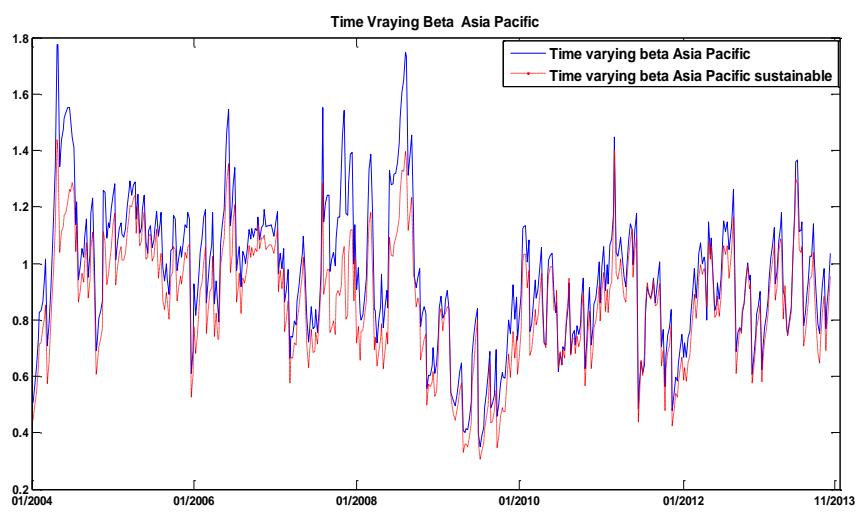

Figure 2 cont.
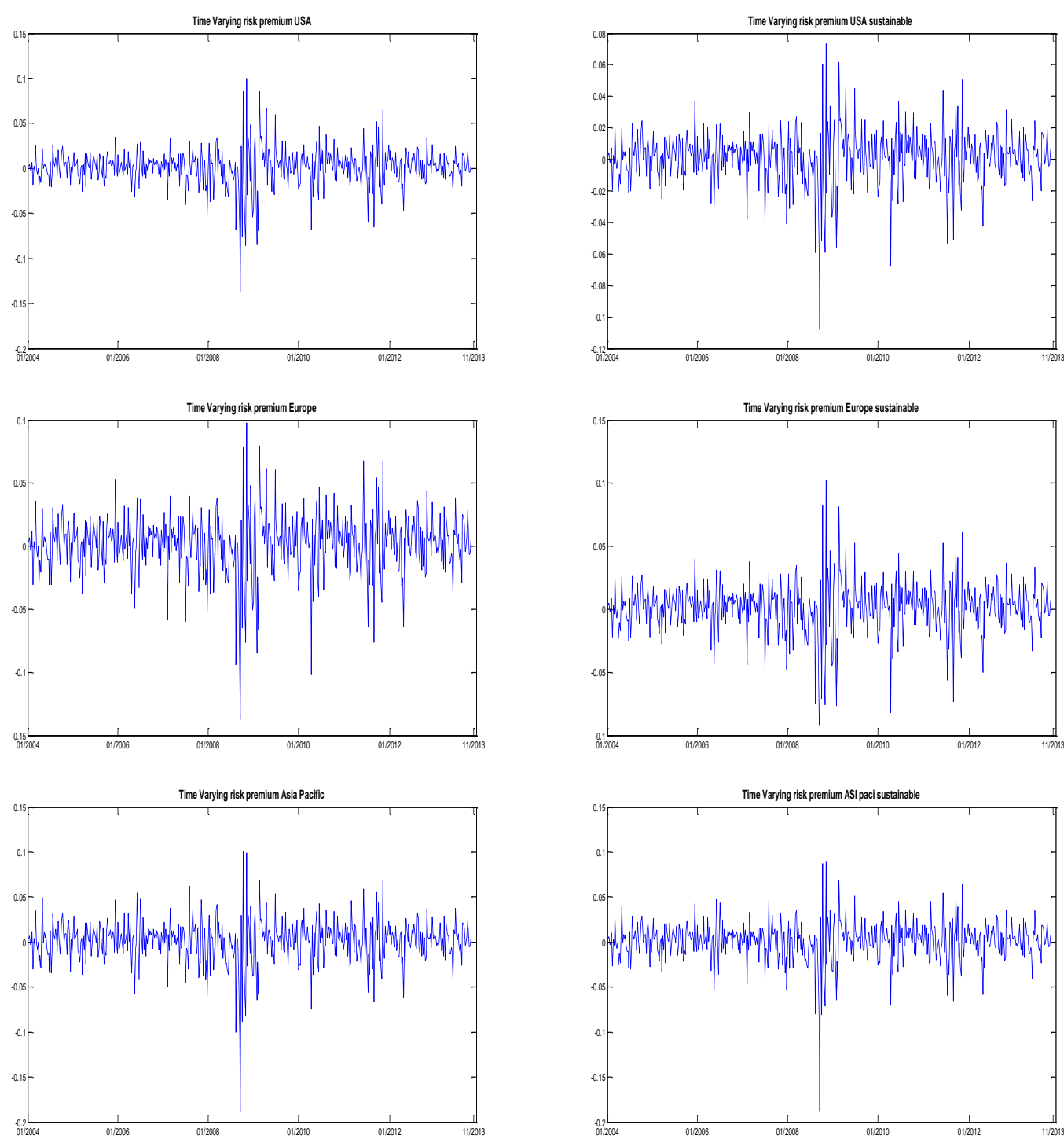

Figure 3: Time-Varying Risk Premium 
Table 2: Mean Beta and Risk Premium - USA

\begin{tabular}{|c|c|c|c|c|}
\cline { 2 - 5 } \multicolumn{1}{c|}{} & \multicolumn{2}{c|}{ USA } \\
\cline { 2 - 5 } \multicolumn{1}{c|}{ Period } & Standard & \multicolumn{2}{c|}{ Sustainable } \\
\hline $01 / 2004-07 / 2007$ & 0.0017 & 0.7525 & 0.0016 & Beta \\
\hline $08 / 2007-08 / 2011$ & $-7.4014 \mathrm{e}-004$ & 0.7637 & $-6.1592 \mathrm{e}-004$ & 0.7265 \\
\hline $09 / 2011-11 / 2013$ & 0.0023 & 0.7487 & 0.0020 & 0.6456 \\
\hline
\end{tabular}

Table 3: Mean Beta and Risk Premium - Europe

\begin{tabular}{|c|c|c|c|c|}
\multicolumn{1}{c|}{} & \multicolumn{3}{c|}{ Europe } \\
\cline { 2 - 6 } \multicolumn{1}{c|}{} & Standard & \multicolumn{3}{c|}{ Sustainable } \\
\hline Period & Risk Premium & Beta & Risk Premium & Beta \\
\hline $01 / 2004-07 / 2007$ & 0.0023 & 1.0671 & 0.0018 & 0.8360 \\
\hline $08 / 2007-08 / 2011$ & $-9.7307 \mathrm{e}-004$ & 0.8995 & $-7.1094 \mathrm{e}-004$ & 0.7616 \\
\hline $09 / 2011-11 / 2013$ & 0.0028 & 1.0274 & 0.0023 & 0.8292 \\
\hline
\end{tabular}

Table 4: Mean Beta and Risk Premium - Asia Pacific

\begin{tabular}{|c|c|c|c|c|}
\cline { 2 - 5 } \multicolumn{1}{c|}{} & \multicolumn{3}{c|}{ Asia Pacific } \\
\cline { 2 - 5 } \multicolumn{1}{c|}{ Period } & Risk Premium & Beta & Risk Premium & Bustainable \\
\hline $01 / 2004-07 / 2007$ & 0.0023 & 1.0642 & 0.0022 & 0.9558 \\
\hline $08 / 2007-08 / 2011$ & -0.0013 & 0.8977 & -0.0011 & 0.7898 \\
\hline $09 / 2011-11 / 2013$ & 0.0024 & 0.8999 & 0.0022 & 0.8422 \\
\hline
\end{tabular}

Table 5: Parameters and Significance

\begin{tabular}{|c|c|c|c|c|c|c|c|}
\hline & & $\begin{array}{c}\text { Dow Jones } \\
\text { USA }\end{array}$ & $\begin{array}{c}\text { Dow Jones } \\
\text { USA } \\
\text { Sustainable }\end{array}$ & $\begin{array}{c}\text { Dow Jones } \\
\text { Europe }\end{array}$ & $\begin{array}{c}\text { Dow Jones } \\
\text { Europe } \\
\text { Sustainable }\end{array}$ & $\begin{array}{c}\text { Dow Jones } \\
\text { Asia Pacific }\end{array}$ & $\begin{array}{c}\text { Dow Jones } \\
\text { Asia Pacific } \\
\text { Sustainable }\end{array}$ \\
\hline \multirow{2}{*}{$\mathrm{C}_{11}$} & Coeff & 0.0047 & 0.005124 & 0.007754 & 0.00543 & 0.008239 & 0.007956 \\
\hline & T-stat & 253.871 & 6951.005 & 82.59465 & 10.715 & 71.7207 & 435.571 \\
\hline \multirow{2}{*}{$\mathrm{C}_{21}$} & Coeff & 0.0045 & 0.005598 & 0.005369 & 0.00618 & 0.005351 & 0.005909 \\
\hline & T- stat & 38.966 & 34.2119 & 147.5498 & 2.68903 & 327.3597 & 79.4748 \\
\hline \multirow{2}{*}{$\mathrm{C}_{22}$} & Coeff & 0.002 & 0.002032 & 0.000263 & 0.00261 & 0.004216 & 0.003775 \\
\hline & T-stat & 113.23 & 52.4658 & 111.948 & 6.88 & 105.77335 & 17.56348 \\
\hline \multirow{2}{*}{$\mathbf{A}_{11}$} & Coeff & 0.132 & 0.102441 & 0.08409 & 0.0610098 & 0.150043 & 0.110499 \\
\hline & T-stat & 2.7686 & 3.947371 & 8.522145 & 3.018626 & 3.136951 & 3.830009 \\
\hline \multirow{2}{*}{$\mathbf{A}_{12}$} & Coeff & -0.00775 & -0.015415 & 0.035219 & 0.0521739 & -0.060311 & -0.070886 \\
\hline & T- stat & -3.3337 & -3.24731 & 17.04192 & 0.004913 & -0.08743 & -1.86575 \\
\hline \multirow{2}{*}{$\mathbf{A}_{21}$} & Coeff & -0.0125 & 0.006975 & -0.01207 & -0.081332 & 0.015943 & -0.056154 \\
\hline & T- stat & -3.7295 & 0.207329 & -9.48891 & -0.000747 & 2.261718 & -2.999117 \\
\hline \multirow{2}{*}{$\mathbf{A}_{22}$} & Coeff & 0.1749 & 0.136014 & -0.008431 & 0.0792316 & 0.149675 & 0.143288 \\
\hline & T-stat & 2.96652 & 1.85282 & -3.889214 & 2.0010654 & 2.14 & 4.0178 \\
\hline \multirow{2}{*}{$D_{11}$} & Coeff & 0.35455 & 0.3067 & 0.195044 & 0.2903053 & 0.394748 & 0.314873 \\
\hline & T- stat & 4.8417 & 22.2737 & 12.432175 & 1.003719 & 5.44637 & 2.895904 \\
\hline \multirow{2}{*}{$D_{12}$} & Coeff & 0.01829 & 0.02844 & 0.19265 & 0.100615 & -0.01268 & 0.049619 \\
\hline & T- stat & 0.17407 & 1.103829 & 1.64819 & 0.000874 & -0.78363 & 1.128882 \\
\hline \multirow{2}{*}{$D_{21}$} & Coeff & -0.0013 & -0.002616 & 0.003198 & 0.028112 & 0.01758 & 0.035111 \\
\hline & T-stat & -0.0777 & -0.015368 & 0.4828785 & 0.901123 & 0.586717 & 1.559103 \\
\hline \multirow{2}{*}{$\mathbf{D}_{22}$} & Coeff & 0.33139 & 0.25273 & 0.249381 & 0.282978 & 0.40157 & 0.373598 \\
\hline & T- stat & 11.6325 & 26.389 & 14.0561 & 0.0105139 & 8.60892 & 15.55426 \\
\hline \multirow{2}{*}{$\mathbf{B}_{11}$} & Coeff & 0.9355 & 0.9174 & 0.9389109 & 0.9249864 & 0.89279 & 0.917623 \\
\hline & T- stat & 20.3376 & 445.551 & 319.354 & 2.576371 & 7.194638 & 92.83499 \\
\hline \multirow{2}{*}{$\mathbf{B}_{12}$} & Coeff & -0.0063 & -0.00095 & -0.02968 & 0.003543 & 0.008984 & -0.007849 \\
\hline & T-stat & -0.4323 & -1.326429 & -0.448073 & 0.011934 & 0.398554 & -1.993499 \\
\hline \multirow{2}{*}{$\mathbf{B}_{21}$} & Coeff & -0.0043 & 0.01096 & 0.0070016 & -0.00846 & 0.020466 & -0.006087 \\
\hline & T- stat & -0.1696 & 0.054474 & 0.893915 & -0.50762 & 1.076271 & -0.864601 \\
\hline \multirow{2}{*}{$\mathbf{B}_{22}$} & Coeff & 0.94138 & 0.919292 & 0.936385 & 0.92711 & 0.887042 & 0.899506 \\
\hline & T-stat & 136.85 & 7.74829 & 19.19731 & 3.01137 & 53.80597 & 29.68952 \\
\hline
\end{tabular}


Finally, Table 5 presents our results related to the asymmetry of our data. The parameters $A_{i i}$ and $A_{i j}$ respectively measure the effect of shocks on own index volatility and the effect of market index i's shock on index $j$ 's volatility. The latter parameter allows us to measure the linkages between index $i$ and market $j$. All the ARCH coefficients $\left(\mathrm{A}_{11}\right.$ and $\left.\mathrm{A}_{22}\right)$ are significantly different from zero, implying volatility clustering. On average, the parameter values of conventional indexes are higher than the parameters of sustainable indexes. This result indicates that market shocks have a greater impact on conventional index volatility than on SRI index volatility. Parameters $D_{i i}$ and $D_{i j}$ measure the additional effects of negative past returns or leverage effect, while parameters $D_{11}$ and $D_{22}$ are significantly different from zero, even at $1 \%$ level for all regional indexes except for the DJ Europe Sustainable. The asymmetric effect is more significant for the conventional indexes (e.g., $\mathrm{D}_{11}=0.3947$ for DJ Asia Pacific) than for sustainable indexes (e.g., D11 $=0.314873$ for DJ Asia Pacific Sustainable). Parameters $B_{i i}$ and $B_{i j}$ respectively measure the own past volatility effect on their conditional variance, and the effects of past volatility of market index $i$ on index $j$ 's conditional variance. Parameters $B_{11}$ and $B_{22}$ are all positive and significantly different from zero, even at a $1 \%$ significance level. The parameter values approach the value of 1 , which means that the conditional volatility of the regional indexes and the global market index are persistent.

\section{CONCLUSION}

In this paper, we studied socially responsible investment (SRI). More specifically, we conducted a comparative study with standard indexes using a conditional CAPM model. We used an asymetric bivariate GARCH model (BEKK GARCH $(1,1)$ ) to estimate the conditional betas and the varying risk premiums. Our results show that each of the three regions we studied has its own specificity. The USA was considerably affected by the subprime crisis. In fact, the crisis changed investment choice criteria to some extent as the level of conditional betas shows that the market now makes a greater distinction between conventional and sustainable investment. In Europe, SRI criteria is still considered by investors as a less risky kind of investment, even if the crisis had a major impact on the level of betas and risk premium. Finally, in Asia Pacific, where markets are evolving and the corporate socially responsible (CSR) industry is less developed, our results show that the sustainable index experienced far lower systematic risk and risk premiums during the whole test period, without being impacted by the international financial crisis. Our findings suggest that the asymmetric effect is more significant for conventional indexes than for sustainable ones.

\section{ACKNOWLEDGEMENTS}

The authors would like to thank the participants of the Third International Symposium in Computational Economics and Finance, Paris, 2014, for their valuable comments and discussions. All remaining errors are our own.

\section{AUTHOR INFORMATION}

Hachmi Ben Ameur, Ph.D. in Management from Cergy Pontoise University, is an Associate Professor of Finance at INSEEC Business School, France. His principal research areas concern financial markets, portfolio management, structured products, insurance portfolio, behavioral finance, and financial econometrics. He has previously published in the European Journal of Operational Research, Economic Modelling, and Applied Economics. E-mail: hbenameur@inseec.com (Corresponding author)

Jérôme Senanedsch, Ph.D. in Management from Sorbonne University, is an Associate Professor of Finance and serves as the Dean of Academics (MBA programs) at INSEEC Business School, France. His principal research areas concern portfolio management, forecasting strategies, and algorithmic trading. He also serves as a consultant and develops new investment strategies for financial institutions, financial data vendors, and software corporations. E-mail: jsenanedsch@inseec.com

\section{REFERENCES}

1. Adler, T., \& Kritzman, M. (2008). The cost of socially responsible investing. Journal of Portfolio Management, 35(1), 52-56.

2. Allen, F., Carletti, E., \& Marquez, R. (2007). Stakeholder capitalism, corporate governance and firm value. (Working Paper). University of Pennsylvania.

Copyright by author(s); CC-BY 
3. Barnea, A., \& Rubin, A. (2010). Corporate social responsibility as a conflict between shareholders. Journal of Business Ethics, 97(1), 71-86.

4. Baron, D. (2001). Private politics, corporate social responsibility, and integrated strategy. Journal of Economic Management and Strategy, 10(1), 7-45.

5. Blanchett, D. M. (2010). Exploring the cost of investing in socially responsible mutual funds: An empirical study. Journal of Investing, 19(3), 93-103.

6. Bollen, N. (2007). Mutual fund attributes and investor behavior. Journal of Financial and Quantitative Analysis, 42, 683-708.

7. Bollerslev, T. (1986). Generalized autoregressive conditional heteroskedasticity. Journal of Econometrics, 31, 307-327.

8. Bollerslev, T., Engle, R. F., \& Wooldridge, J. M. (1988). A capital asset pricing model with time-varying covariances. Journal of Political Economy, 96, 116-131.

9. Bollerslev, T., \& Wooldridge J. M. (1992). Quasi-maximum likelihood estimation and inference in dynamic models with time-varying covariances. Econometric Reviews, 1, 143-173.

10. Collison, D. J., Cobb, G., Power, D. M., \& Stevenson, L. A. (2008). The financial performance of the FTSE4Good Indices. Corporate Social Responsibility and Environmental Management, 15, 14-28.

11. DiBartolomeo, D., \& Kurtz, L. (1999). Managing risk exposures of socially screened portfolios. Northfield Information Services, Boston.

12. Engle, R. F. (1982). Autoregressive conditional heteroskedasticity with estimates of the variance of U.K. inflation. Econometrica, 50, 987-1008.

13. Engle, R. F., \& Kroner, K. F. (1995). Multivariate simultaneous generalized ARCH. Econometric Theory, $11,122-150$.

14. Fatoum, S., Guesmi K., \& Moschetto B. L. (2014). The evolution of risk premiums in emerging stock markets: The case of Latin America and Asia region. Journal of Applied Business Research, 30(2), 353359.

15. Fisman, R., Heal, G., \& Nair, V. (2006). A model of corporate philanthropy. (Working Paper). Columbia University.

16. Heal, G. (2005). Corporate social responsibility: An economic and financial framework. The Geneva Papers on Risk and Insurance - Issues and Practice, 1-23.

17. Jagannathan, R., \& Wang, Z. (1996). The conditional CAPM and the cross-section of expected returns. Journal of Finance, 51, 3-53.

18. Klassen, R., \& McLaughlin, C. (1996). The impact of environmental management on firm performance. Management Science, 42(8), 1199-1214.

19. Kroner, K. F., \& Ng, V. K. (1998). Modeling asymmetric comovements of asset returns. The Review of Financial Studies, 11, 817-844.

20. Lyn, E. O., \& Zychowicz, E. J. (2010). The impact of faith-based screens on investment performance. Journal of Investing, 19(3), 136-143.

21. Nikkinen, J., Saleem K., \& Martikainen, M. (2013), Transmission of the subprime crisis: Evidence from industrial and financial sectors of BRIC countries. Journal of Applied Business Research, 29(5), 14691478.

22. Orlitzky, M., Schmidt, F., \& Rynes, S. (2003). Corporate social and financial performance: A metaanalysis. Organization Studies, 24(3), 403-411.

23. Renneboog, L., Ter Horst, J., \& Zhang, C. (2008a). Socially responsible investments: Institutional aspects, performance, and investor behavior. Journal of Banking \& Finance, 32, 1723-1742.

24. Renneboog, L., Ter Horst, J., \& Zhang, C. (2008b). The price of ethics and stakeholder governance: The performance of socially responsible mutual funds. Journal of Corporate Finance, 14(3), 302-322.

25. Sauer, D. (1997). The impact of social-responsibility screens on investment performance: Evidence from the Domini Social Index and Domini Equity Mutual Fund. Review of Financial Economics, 6, 137-149.

26. Sharpe, W. (1964). Capital asset prices: A theory of market equilibrium under conditions of risk. Journal of Finance, 9, 725-742.

27. Statman, M. (2006). Socially responsible indexes: Composition, performance and tracking error. Journal of Portfolio Management, Spring, 100-109. 


\section{NOTES}

